\title{
Physical Modeling Study on Combined Side and Top Blowing AOD Refining Process of Stainless Steel: Fluid Mixing Characteristics in Bath
}

\author{
Ji-He WEI, ${ }^{1)}$ Hong-Li ZHU, ${ }^{1)}$ He-Bing $\mathrm{CHI}^{2)}$ and Hai-Jiang WANG ${ }^{1)}$ \\ 1) Department of Metallic Materials, College of Materials Science and Engineering, Shanghai University, Shanghai, 200072, P. \\ R. China. $\quad$ 2) Stainless Steel Branch, Baoshan Iron \& Steel Co., Ltd., Shanghai, 200431, P. R. China.
}

(Received on June 6, 2009; accepted on September 30, 2009)

\begin{abstract}
Based on water modeling of the gas stirring and fluid flow in the bath, the fluid mixing characteristics in the bath during the combined side and top blowing AOD refining process of stainless steel were studied on a water model unit of a 120 t AOD converter. The influences of the angle included between each tuyere, the side tuyere number and the gas flow rates for both side and top blowing on the characteristics were examined. The results illustrated that the combined side and top blowing process possessed a good mixing effectiveness. The gas flow rate of the main tuyeres had a key role on the liquid mixing in the bath. With a physical shielding effect of the gas streams from the subtuyeres on the gas streams of the main tuyeres, increasing suitably the gas flow rate of the subtuyeres could enhance mixing efficiency; and the gas jet of the top lance could prolong the mixing time. For a simple side blowing, at a given tuyere number and gas side blowing rate, an increase in the angular separation between each tuyere could be advantageous for shortening the mixing time. At a given angle between each tuyere and gas side blowing rate, increasing the tuyere number could not necessarily reach definitely a similar result. Moreover, it could make the high temperature zone move towards the sidewall around the tuyere outlets and lower the life of the refractory lining due to reducing the gas flow rate of single tuyere and the horizontal penetration of the gas stream. Relevant to the oxygen top bowing rate of $6600 \mathrm{Nm}^{3} / \mathrm{h}$ used in the practice, taking 5 tuyeres with $22.5^{\circ}$ or 6 tuyeres with $27^{\circ}$ could offer a roughly equivalent and good mixing result. As far as only the mixing in the bath is concerned, for the 120 t AOD converter, the existing 7 tuyeres with $18^{\circ}$ would not be a proper equipment and arrangement of tuyere under the blowing operations employed for the practical refining. Using 6 tuyeres with $27^{\circ}$ could give a perfect mixing in all the various refining periods. The relationships of the mixing time with the gas blowing rates of main tuyeres and subtuyeres and top lance, the angle between each tuyere, the tuyere number, the agitation power densities, and the modified Froude numbers were determined.
\end{abstract}

KEY WORDS: stainless steel; AOD refining; combined side and top blowing; fluid mixing characteristics; physical modeling.

\section{Introduction}

The available results ${ }^{1-3)}$ indicated that during the combined side and top blowing AOD (argon-oxygen decarburization) refining process of stainless steel, the fluids in the bath are same in considerably violent agitation and circulatory motion, and there is no marked dead zone in the bath. However, the gas stirring and fluid flow in the bath have still some different characteristics from those during a traditional simple side blowing AOD process, which must be able to make the distinct mixing in the bath. For the fluid mixing phenomenon in an AOD bath during the combined blowing process, the concerned reports in the literature are very few. Fabritius et $a l^{4-6)}$ conducted water modeling studies on the fluid flow and mixing and so on in the bath during the combined blowing process of stainless steel in a $90 \mathrm{t}$ AOD converter. However, they did not ensure sufficiently full kinematic similarity between the model and its proto- type in their experiments; also, they considered the influence of the gas jet from the top lance on the fluid flow and mixing in the bath being not large and neglected its role. At the prerequisite of maintaining the kinematic similarity between the model and its prototype as high as possible, Wei et $a l^{2,3)}$ carried out preliminarily the physical modeling of the combined blowing refining of stainless steel in a $120 \mathrm{t}$ AOD converter. Since the converter was under construction at that time, some key data could only be set up according to the technological design and had larger disparities from the practice, leading to the kinematic similarity between the model and its prototype being also not high enough. Taken the $120 \mathrm{t}$ AOD converter completed and put into operation as a prototype, based on the water modeling of the gas stirring and fluid flow in the bath with sufficiently full kinematic similarity of the model to its prototype, ${ }^{1)}$ the fluid mixing characteristics in the bath during the refining process of stainless steel were investigated. The related re- 
sults are reported in the paper.

\section{Experiments and Conditions}

The experiments were performed on a water model unit shown schematically in Fig. 1, which was entirely the same as that given in Ref. 1). The measurement method for mixing time of the liquid in the bath and experimental procedures were also the same as those used in the preliminary investigation. $^{2,3)}$ The electrical conductivity method was taken. After the gas blowing rate of a specified value was reached and stabilized, without changing the liquid flow pattern in the model bath, a saturated $\mathrm{KCl}$ solution of $150 \mathrm{~mL}$ was added to the liquid surface in about $1 \mathrm{~s}$, and the adding point was fixedly located near the wall above the sector zone between the outer two tuyeres. An electrode probe of DSJ-1 model was set up in the relatively stagnant region of the liquid in the model bath, which was located opposite the side tuyeres at about $10 \mathrm{~mm}$ from the bottom and the sidewall. The changes in the electrical conductivity of the aqueous solution were monitored by an electrical conductivity meter of DSS-IIA model with the probe. In addition, an automatic balance $\mathrm{X}-\mathrm{Y}$ function recorder uninterruptedly and automatically recorded the appropriate output signals (see Fig. 1). The mixing time was defined as $\tau_{0.95}$, i.e. the time taken for the variations of electrical conductivity not to exceed $\pm 5 \%$ of the stable value. At each

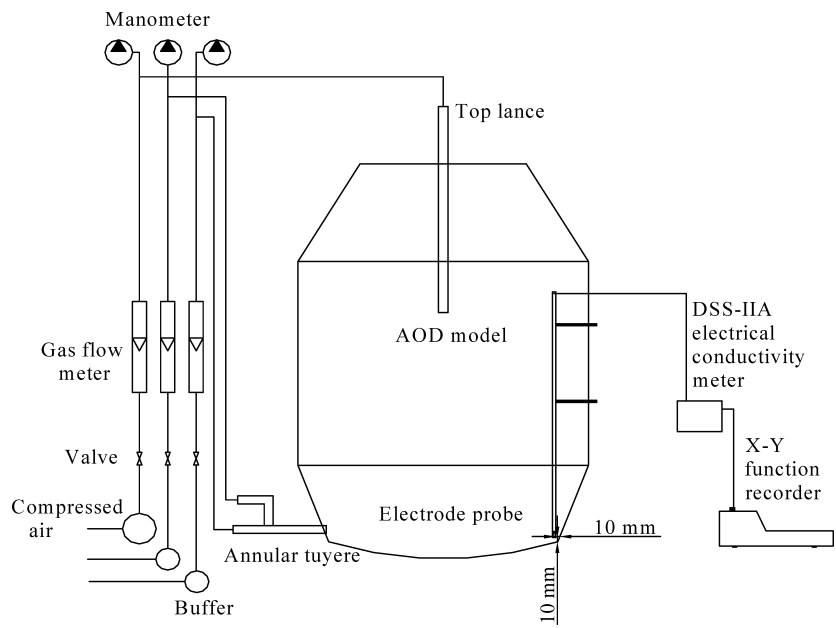

Fig. 1. Schematic diagram of the model unit of the $120 \mathrm{t}$ AOD converter employed for water modeling experiments. operating mode, the measurement was repeated at least 4-5 times, and then an arithmetical average value of the results obtained was taken. However, measurement precisions of the electrode probe of DSJ-1 model and electrical conductivity meter of DSS-IIA model employed here were higher.

The influences of the tuyere number, the angle between each tuyere, the gas flow rates for both side and top blowing were examined. The operating modes were from those used for water modeling of the gas stirring and fluid flow characteristics in the bath during the refining process, ${ }^{1)}$ collected in Table 1.

\section{Experimental Results}

Some results for the mixing time obtained experimentally in the model bath of the $120 \mathrm{t}$ AOD converter under different operating modes are shown in Figs. 2-14. Here, Figs. 2-8 present the relationship of the time with the angular separation between each tuyere under the conditions of the simple side and combined blowing with different gas blowing rates at a given tuyere number, respectively.
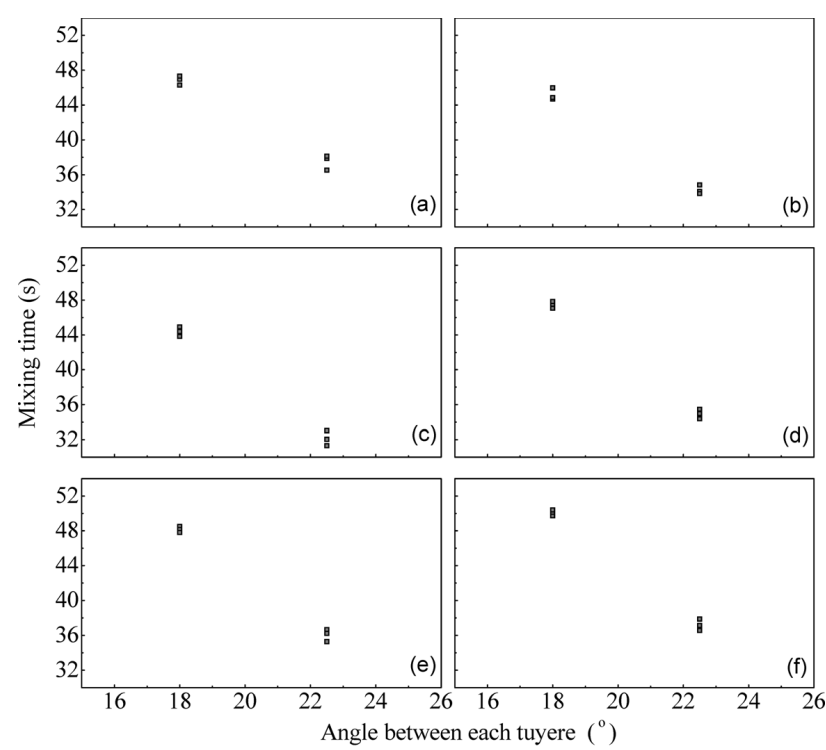

Side blowing; Tuyere number: 7; Total gas flow rate $\left(\mathrm{Nm}^{3} / \mathrm{h}\right): \mathrm{a}-50.77$ b-61.74 c-70.35 $\quad d-82.67 \quad$ e-86.81 f-101.78

Fig. 2. Relationship of mixing time in the $120 \mathrm{t}$ AOD model bath to angle between each tuyere in simple side blowing at a given tuyere number of 7 and gas blowing rate.

Table 1. All the operating modes utilized for water modeling experiments in the present work.

\begin{tabular}{|c|c|c|c|c|c|c|}
\hline \multirow{2}{*}{$\begin{array}{l}\text { Assumed situation of gas stream in side tuyere } \\
\text { used for the prototype }{ }^{(*)}\end{array}$} & I & II & III & IV & $\mathrm{V}$ & VI \\
\hline & 1 & $1+3$ & $1+3+4$ & 2 & $2+3$ & $2+3+4$ \\
\hline \multicolumn{7}{|l|}{ Total gas flow rate for side tuyeres, $\mathrm{Nm}^{3} / \mathrm{h}$} \\
\hline for main tuyere $\left(Q_{\mathrm{m}}\right)$ & 45.49 & 62.92 & 79.38 & 52.12 & 73.05 & 92.16 \\
\hline for subtuyere $\left(Q_{\mathrm{s}}\right)$ & 5.28 & 7.43 & 7.43 & 9.62 & 9.62 & 9.62 \\
\hline \multirow{3}{*}{ Top gas blowing rate $\left(Q_{\mathrm{t}}\right), \mathrm{Nm}^{3} / \mathrm{h}$} & \multicolumn{2}{|c|}{ No. 1} & \multicolumn{2}{|c|}{ No. 2} & \multicolumn{2}{|c|}{ No. 3} \\
\hline & \multicolumn{2}{|c|}{79.87} & \multicolumn{2}{|c|}{72.61} & \multicolumn{2}{|c|}{65.35} \\
\hline & No.1 & & No.2 & & & No.4 \\
\hline \multirow{2}{*}{$\begin{array}{l}\text { Side tuyere number/Angular separation between each } \\
\text { tuyere, deg }\end{array}$} & 7 & & 6 & & & 4 \\
\hline & $\overline{18,22.5}$ & & $\overline{18,22.5,27}$ & $\overline{18,2}$ & $27,31.5$ & $\overline{45}$ \\
\hline Liquid height above tuyere axis, $\mathrm{m}$ & \multicolumn{5}{|c|}{ Distance of top lance outlet from bath surface, $\mathrm{m}$} & 0.500 \\
\hline
\end{tabular}



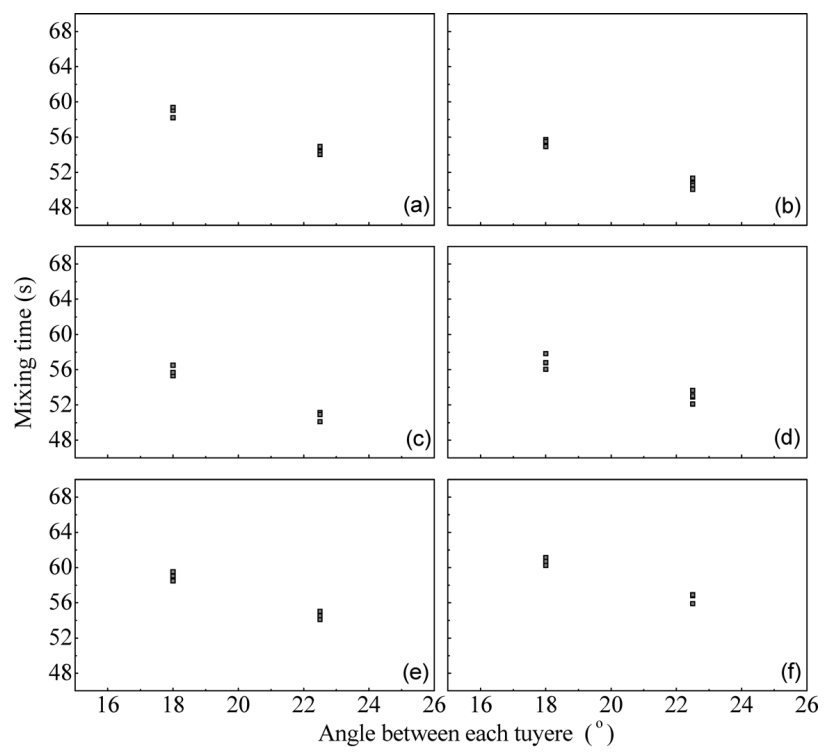

Combined blowing; Tuyere number: 7; Top blowing gas flow rate: $79.87 \mathrm{Nm}^{3} / \mathrm{h}$; Gas side blowing rate $\left(\mathrm{Nm}^{3} / \mathrm{h}\right):$ a $-50.77 \quad \mathrm{~b}-61.74$ c-70.35 $\quad d-82.67 \quad$ e- $86.81 \quad f-101.78$

Fig. 3. Relationship of mixing time in the $120 \mathrm{t}$ AOD model bath to angle between each tuyere in combined side and top blowing with a gas top blowing rate of $79.87 \mathrm{Nm}^{3} / \mathrm{h}$ (relevant to the practical operating mode) at a given tuyere number of 7 and gas side blowing rate.

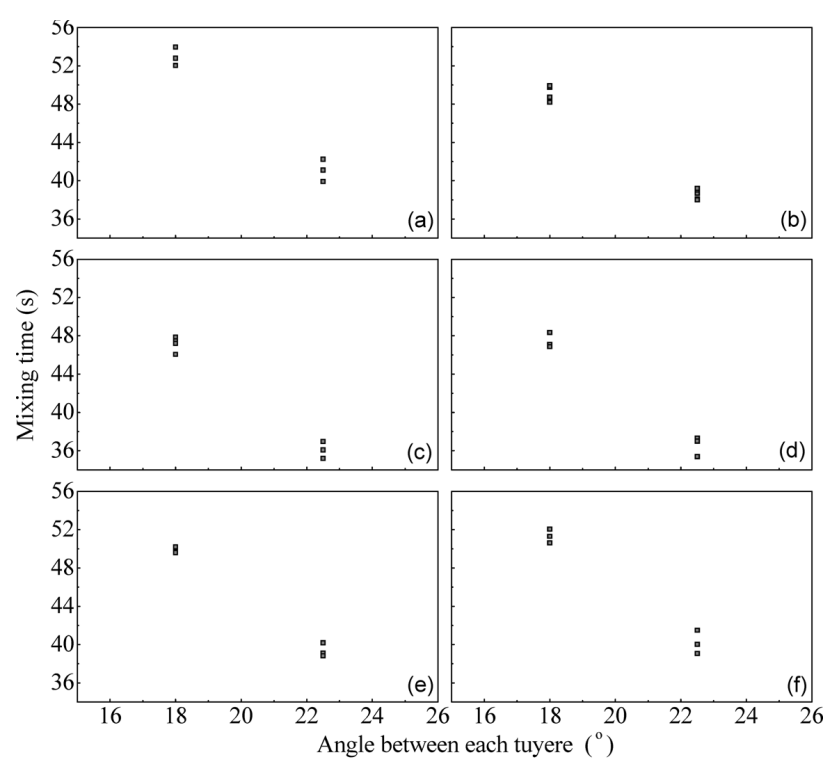

Combined blowing; Tuyere number: 7; Top blowing gas flow rate: $65.35 \mathrm{Nm}^{3} / \mathrm{h}$; Gas side blowing rate $\left(\mathrm{Nm}^{3} / \mathrm{h}\right):$ a-50.77 b-61.74 c-70.35 d-82.67 e-86.81 f-101.78

Fig. 4. Relationship of mixing time in the $120 \mathrm{t}$ AOD model bath to angle between each tuyere in combined side and top blowing with a gas top blowing rate of $65.35 \mathrm{Nm}^{3} / \mathrm{h}$ at a given tuyere number of 7 and gas side blowing rate.

Figures 9-11 illustrate the relationship of the time with the tuyere number under the conditions of the simple side and combined side and top blowing with different gas blowing rates at a given angle between each tuyere, separately. Figures $12-14$ give the changes in the time with the total gas blowing rate under the conditions of the simple side and combined blowing at a given tuyere number and an angular separation between each tuyere, respectively. The gas flow rates given in these figures are the sum of the total rates
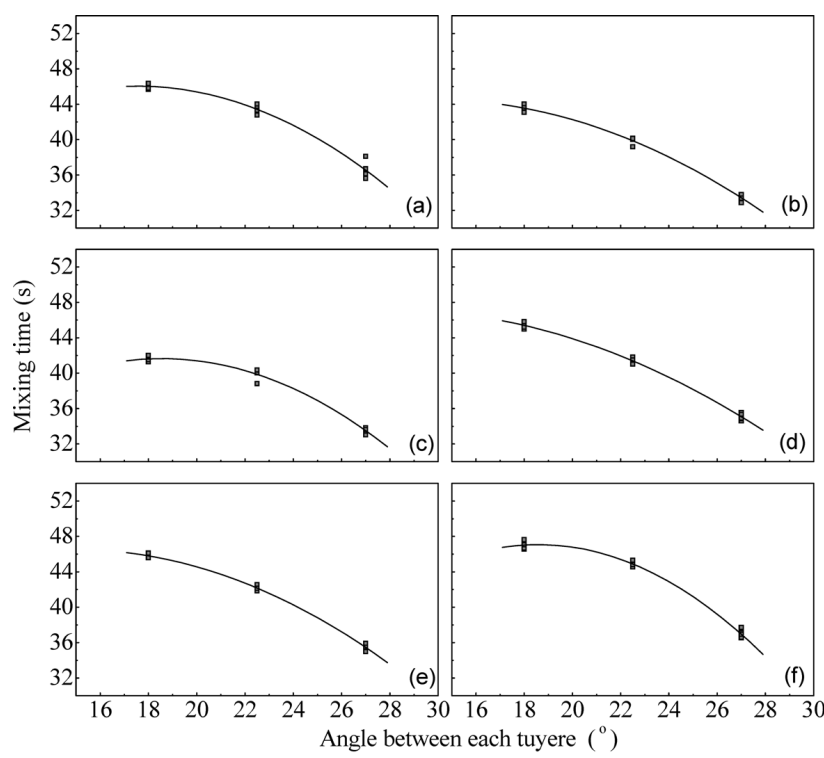

Side blowing; Tuyere number: 6 ; Total gas flow rate $\left(\mathrm{Nm}^{3} / \mathrm{h}\right)$ : a-50.77

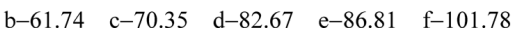

Fig. 5. Relationship of mixing time in the $120 \mathrm{t}$ AOD model bath to angle between each tuyere in simple side blowing at a given tuyere number of 6 and gas blowing rate.

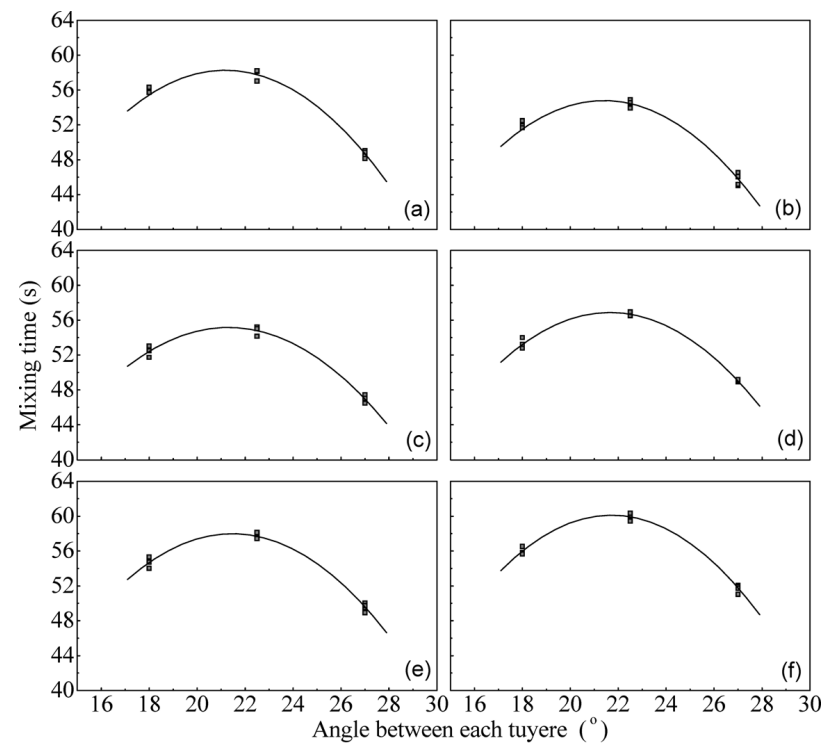

Combined blowing; Tuyere number: 6; Top blowing gas flow rate: $79.87 \mathrm{Nm}^{3} / \mathrm{h}$; Gas side blowing rate $\left(\mathrm{Nm}^{3} / \mathrm{h}\right)$ : a-50.77 b-61.74 c-70.35 d-82.67 e-86.81 f-101.78

Fig. 6. Relationship of mixing time in the $120 \mathrm{t}$ AOD model bath to angle between each tuyere in combined side and top blowing with a gas top blowing rate of $79.87 \mathrm{Nm}^{3} / \mathrm{h}$ (relevant to the practical operating mode) at a given tuyere number of 6 and gas side blowing rate.

from both the main tuyeres and subtuyeres for the simple side blowing, and the sum of the total side blowing rate and the top blowing rate for the combined blowing. Due to the limit of space, only a small part of the experimental results are given here, but the mixing characteristics in the bath during the refining process can still fully be demonstrated. It is very clear that this refining process has a good mixing efficiency. Compared to the data obtained in the preliminary investigation, ${ }^{2,3)}$ the results obtained would be more approach the real situations in the prototype because of 


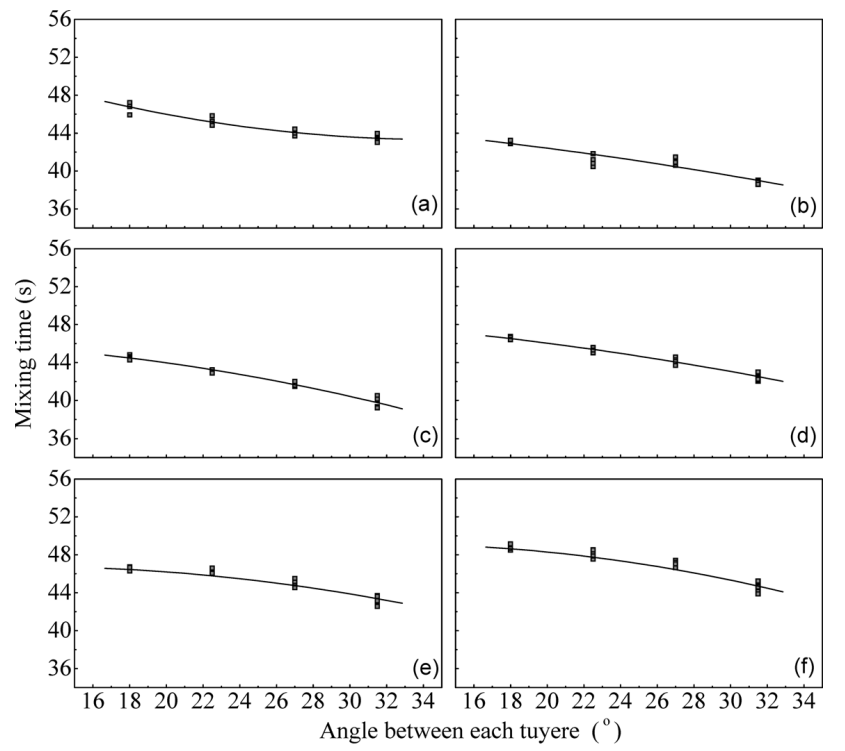

Side blowing; Tuyere number: 5 ; Total gas flow rate $\left(\mathrm{Nm}^{3} / \mathrm{h}\right): \mathrm{a}-50.77$ b-61.74 c-70.35 $\quad$ d-82.67 $\quad$ e-86.81 f-101.78

Fig. 7. Relationship of mixing time in the $120 \mathrm{t}$ AOD model bath to angle between each tuyere in simple side blowing at a given tuyere number of 5 and gas blowing rate.
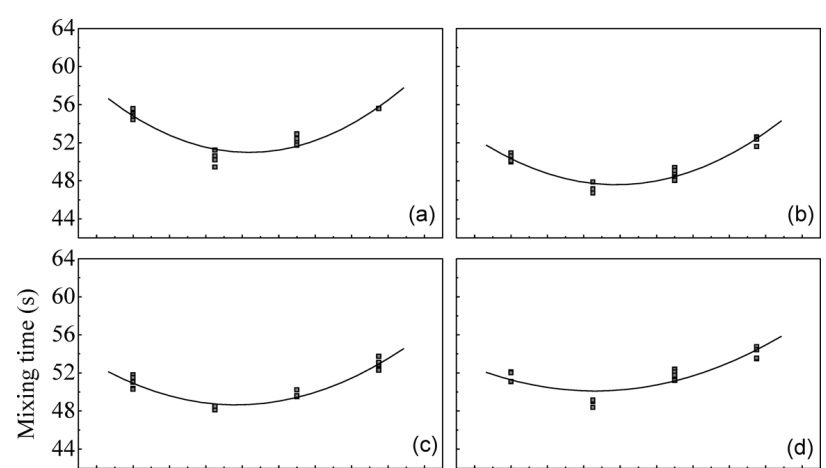

(c)

(d)

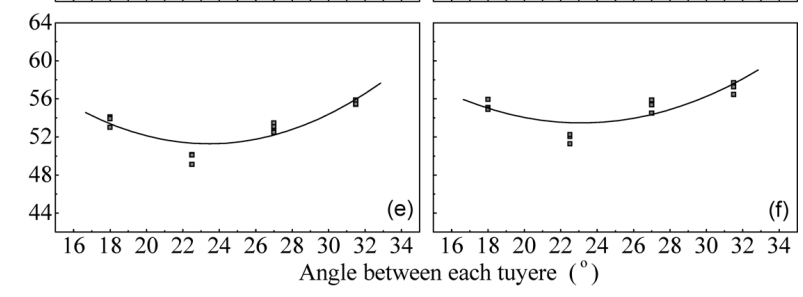

Combined blowing; Tuyere number: 5 ; Top blowing gas flow rate: $79.87 \mathrm{Nm}^{3} / \mathrm{h}$; Gas side blowing rate $\left(\mathrm{Nm}^{3} / \mathrm{h}\right): \mathrm{a}-50.77 \quad \mathrm{~b}-61.74$ c-70.35 d-82.67 e-86.81 f-101.78

Fig. 8. Relationship of mixing time in the $120 \mathrm{t}$ AOD model bath to angle between each tuyere in combined side and top blowing with a gas top blowing rate of $79.87 \mathrm{Nm}^{3} / \mathrm{h}$ (relevant to the practical operating mode) at a given tuyere number of 5 and gas side blowing rate.

much higher kinematic similarity of the model with its prototype in the present work, showed a still better mixing effectiveness.

\section{Analysis and Discussion of Results}

\subsection{Influence of Angular Separation between Each Tuyere on Mixing Characteristics}

Figures 2 to 4 showed that in the case of the simple side blowing with 7 tuyeres, the mixing times in the bath corre-

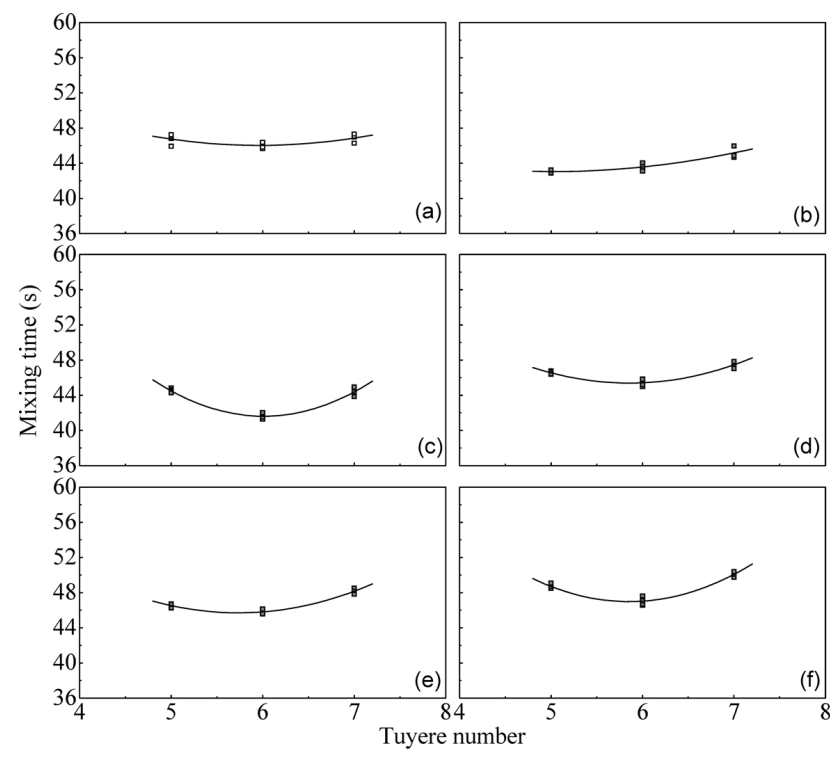

Side blowing; Angle between each tuyere: $18^{\circ}$; Total gas flow rate $\left(\mathrm{Nm}^{3} / \mathrm{h}\right)$

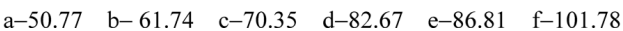

Fig. 9. Relationship of mixing time in the $120 \mathrm{t}$ AOD model bath to tuyere number in simple side blowing at a given angle of $18^{\circ}$ between each tuyere and gas flow rate.

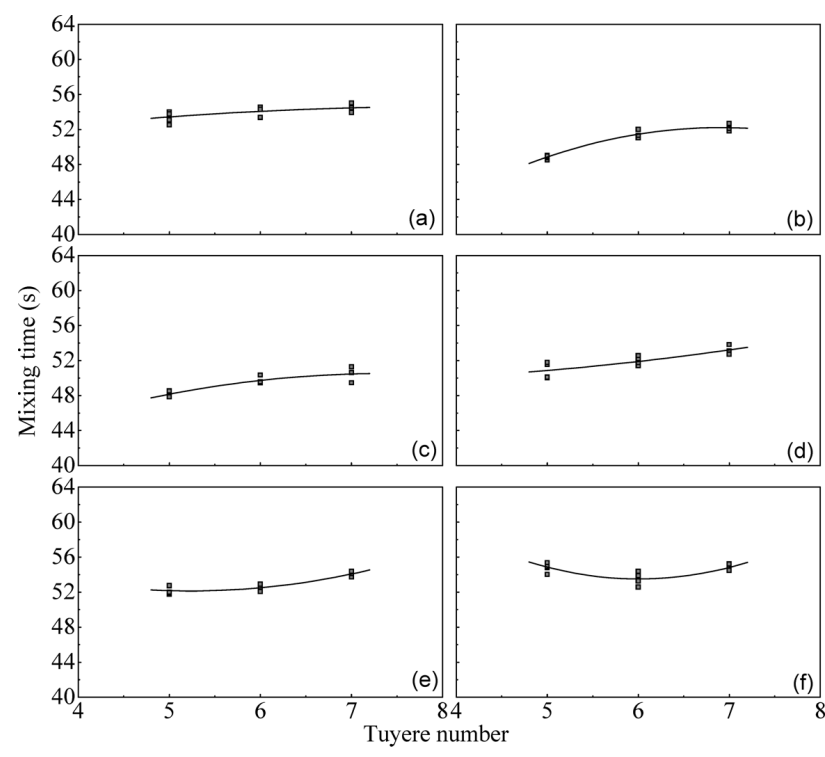

Combined blowing; Top blowing gas flow rate: $72.61 \mathrm{Nm}^{3} / \mathrm{h}$; Angle between each tuyere: $18^{\circ}$; Gas side blowing rate $\left(\mathrm{Nm}^{3} / \mathrm{h}\right)$ : a-50.77 b- $61.74 \quad c-70.35 \quad d-82.67 \quad e-86.81 \quad f-101.78$

Fig. 10. Relationship of mixing time in the $120 \mathrm{t}$ AOD model bath to tuyere number in combined side and top blowing with a gas top blowing rate of $72.61 \mathrm{Nm}^{3} / \mathrm{h}$ at a given angle of $18^{\circ}$ between each tuyere and gas side blowing rate.

sponding to the different gas blowing rates were in the range of (31-51)s. At the given gas flow rates, increasing the angular separation between each tuyere from $18^{\circ}$ to $22.5^{\circ}$ obviously shortened the mixing time in the bath, averagely by about (13-20) s. For the combined blowing with the gas top blowing rates of 79.87 (relevant to the real operating mode) and $65.35 \mathrm{Nm}^{3} / \mathrm{h}$, the mixing times in the bath were respectively (50-61) and (35-51) s (being (41-53) s at a gas top blowing rate of $72.61 \mathrm{Nm}^{3} / \mathrm{h}$ ). Raising the angle between each tuyere from $18^{\circ}$ to $22.5^{\circ}$ also made the mix- 


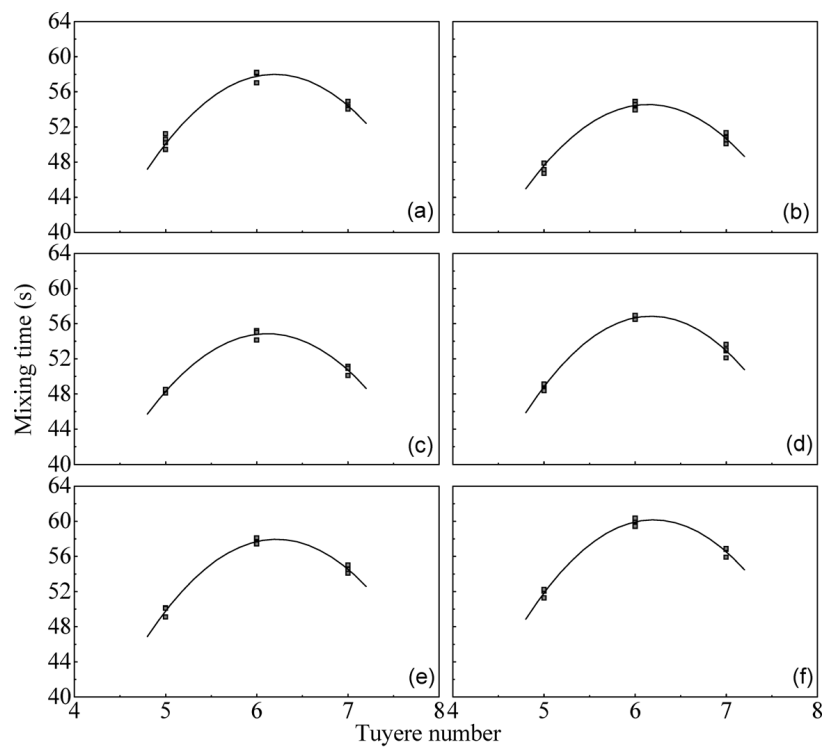

Combined blowing; Top blowing gas flow rate: $79.87 \mathrm{Nm}^{3} / \mathrm{h}$; Angle between each tuyere: $22.5^{\circ}$; Gas side blowing rate $\left(\mathrm{Nm}^{3} / \mathrm{h}\right)$ :

a-50.77 b-61.74 $\quad c-70.35 \quad d-82.67 \quad$ e-86.81 $\quad$ f-101.78

Fig. 11. Relationship of mixing time in the $120 \mathrm{t}$ AOD model bath to tuyere number in combined side and top blowing with a gas top blowing rate of $79.87 \mathrm{Nm}^{3} / \mathrm{h}$ (corresponding to the practical operating mode) at a given angle of $22.5^{\circ}$ between each tuyere and gas side blowing rate.

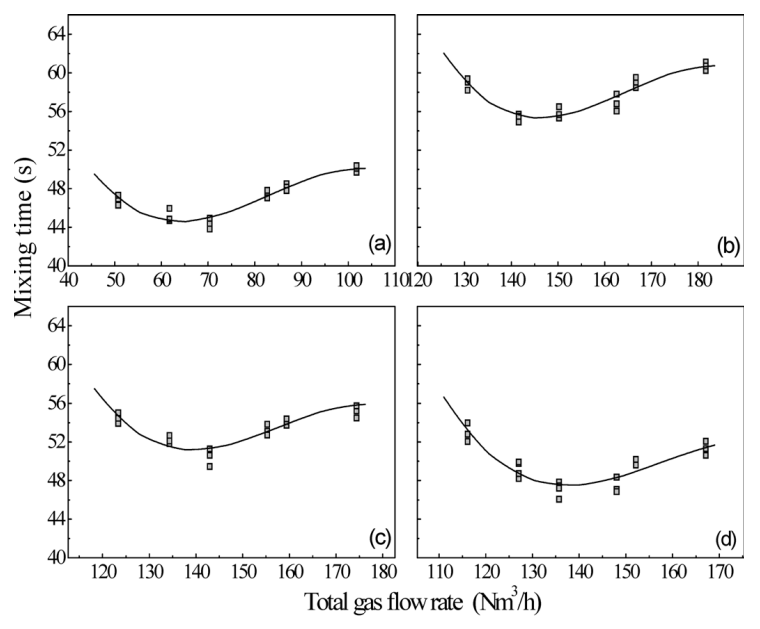

Tuyere number: 7; Angle between each tuyere: $18^{\circ}$; a-side blowing b-combined blowing $\left(Q_{\mathrm{t}}=79.87 \mathrm{Nm}^{3} / \mathrm{h}\right) \quad \mathrm{c}$-combined blowing $\left(Q_{\mathrm{t}}\right.$ $\left.=72.61 \mathrm{Nm}^{3} / \mathrm{h}\right) \quad \mathrm{d}$-combined blowing $\left(Q_{\mathrm{t}}=65.35 \mathrm{Nm}^{3} / \mathrm{h}\right)$

Fig. 12. Changes of mixing time in the $120 \mathrm{t}$ AOD model bath with total gas flow rate under the conditions of simple side and combined blowing at a given tuyere number of 7 and angle of $18^{\circ}$ between each tuyere.

ing time shorten; but compared with that for the simple side blowing, the shortened amplitudes evidently decreased, especially with a higher gas flow rate from the top lance. The experimental results demonstrated that when using 7 tuyeres, for both the simple side blowing and the combined side and top blowing, increasing the angle included between each tuyere from $18^{\circ}$ to $22.5^{\circ}$ would all be favorable for the mixing in the bath.

In the case of using 6 tuyeres to perform the simple side blowing with the same gas blowing rates, the mixing times in the bath were approximately (33-47) s (Fig. 5). Similar to that with 7 tuyeres, the mixing time reduced with in-

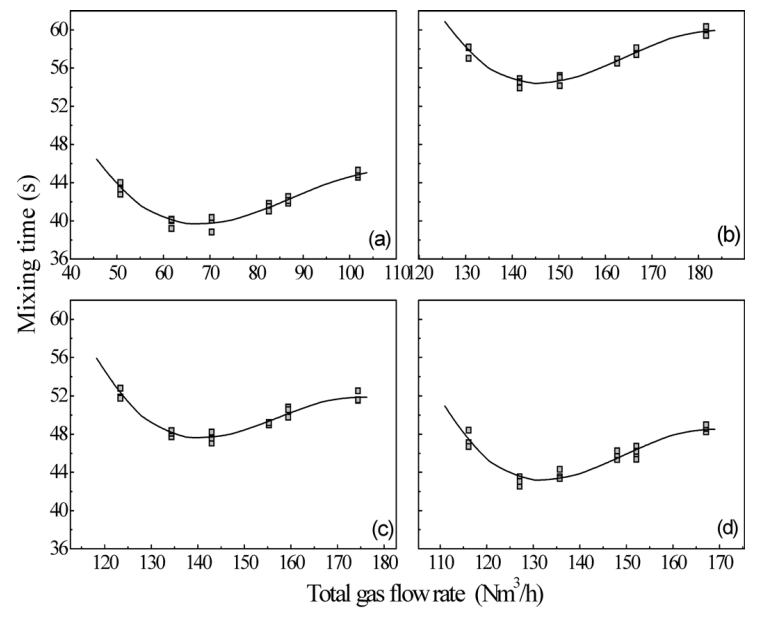

Tyere number: 6; Angle between each tuyere: $22.5^{\circ}$; a-side blowing b-combined blowing $\left(Q_{\mathrm{t}}=79.87 \mathrm{Nm}^{3} / \mathrm{h}\right) \quad \mathrm{c}$-combined blowing $\left(Q_{\mathrm{t}}=\right.$ $\left.72.61 \mathrm{Nm}^{3} / \mathrm{h}\right) \quad \mathrm{d}$-combined blowing $\left(Q_{\mathrm{t}}=65.35 \mathrm{Nm}^{3} / \mathrm{h}\right)$

Fig. 13. Changes of mixing time in the $120 \mathrm{t}$ AOD model bath with total gas flow rate under the conditions of simple side and combined blowing at a given tuyere number of 6 and angle of $22.5^{\circ}$ between each tuyere.

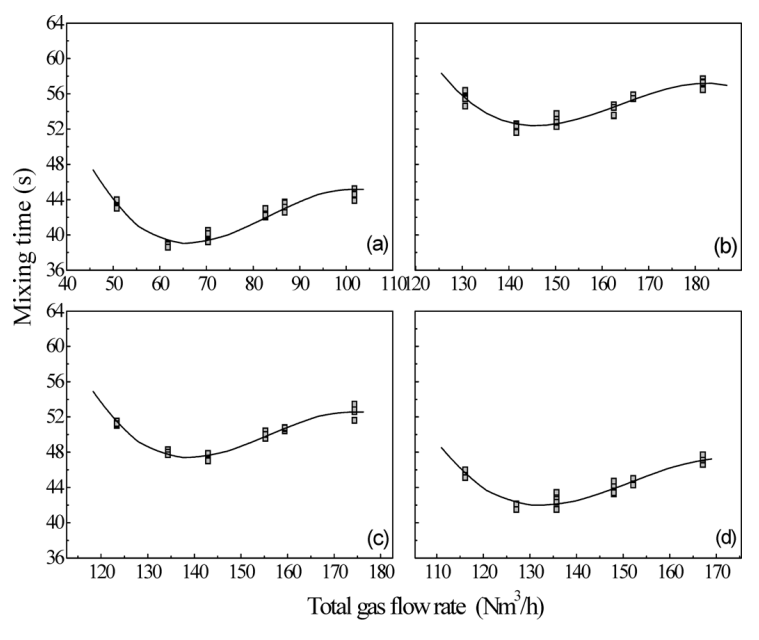

Tuyere number: 5; Angle between each tuyere: $31.5^{\circ}$; a-side blowing b-combined blowing $\left(Q_{\mathrm{t}}=79.87 \mathrm{Nm}^{3} / \mathrm{h}\right) \quad$ c-combined blowing $\left(Q_{\mathrm{t}}=\right.$ $\left.72.61 \mathrm{Nm}^{3} / \mathrm{h}\right) \quad \mathrm{d}$-combined blowing $\left(Q_{\mathrm{t}}=65.35 \mathrm{Nm}^{3} / \mathrm{h}\right)$

Fig. 14. Changes of mixing time in the $120 \mathrm{t}$ AOD model bath with total gas flow rate under the conditions of simple side and combined blowing at a given tuyere number of 5 and angle of $31.5^{\circ}$ between each tuyere.

creasing the angular separation between each tuyere from $18^{\circ}$ to $27^{\circ}$, the appropriate lowered amplitude being about $(8-14)$ s. For the combined blowing with the gas top blowing rates of $79.87,72.61$ and $65.35 \mathrm{Nm}^{3} / \mathrm{h}$, the mixing times were respectively (47-60) (Fig. 6), (42-54) and (38-52)s, reaching an approximately equivalent mixing effectiveness to those with 7 tuyeres. The curves given in Figs. 5 and 6 were obtained all by fitting of the experimental data in terms of quadratic polynomial. With a gas top blowing rate of $79.87 \mathrm{Nm}^{3} / \mathrm{h}$, there was a maximal value of the mixing time at an angle of about $22.5^{\circ}$; the time was shortest at an angular separation of $27^{\circ}$. At the gas top blowing rate of 72.61 or $65.35 \mathrm{Nm}^{3} / \mathrm{h}$, increasing the angle between each tuyere from $18^{\circ}$ to $27^{\circ}$ made the appropriate mixing time monotonously decrease, like that of the combined blowing with 7 tuyeres. The reduced amplitude values were about 
(7-12) s, also smaller than those for the simple side blowing. Under the conditions of the present work, if only considering mixing in the bath, for both simple side and combined blowing with 6 tuyeres, it had all better taking an angular separation of $27^{\circ}$ between each tuyere.

When using 5 tuyeres, the changing pattern of the mixing time in the bath with the angle between each tuyere for the simple side blowing was same as that for using 6 or 7 tuyeres, i.e. the larger the angular separation, the shorter the mixing time was. However, increasing the angle between each tuyere from $18^{\circ}$ to $31.5^{\circ}$ only made the mixing time in the bath shortening by (3-6) s; at the same gas blowing rates, the corresponding mixing times in the bath were approximately (38-48)s (Fig. 7). For the combined blowing with a gas top blowing rate of $79.87 \mathrm{Nm}^{3} / \mathrm{h}$, the mixing times in the bath were about (48-58) s (Fig. 8), and being (43-56) and (39-53) s respectively with the gas flow rates of 72.61 and $65.35 \mathrm{Nm}^{3} / \mathrm{h}$, basically, equivalent to the mixing results of using 7 or 6 side tuyeres. However, at a larger gas top blowing rate, the mixing time presented a minimal value with increasing of the angle between each tuyere, different from the situation of using 7 or 6 side tuyeres. For the combined blowing process with a gas top blowing rate of $79.87 \mathrm{Nm}^{3} / \mathrm{h}$ and the gas side blowing rates of 92.16 and $9.62 \mathrm{Nm}^{3} / \mathrm{h}$ respectively from the main tuyeres and subtuyeres, there was $\tau_{\mathrm{m}}=0.059 \theta^{2}-2.724 \theta+84.970$ in the range of $\left(18^{\circ}-31.5^{\circ}\right)$ (Fig. $8(\mathrm{f})$ ). The mixing time in the bath was shortest at an angular separation of $\theta=23.085^{\circ}$ between each tuyere. At a gas top blowing rate of $72.61 \mathrm{Nm}^{3} / \mathrm{h}$ and the same gas side blowing rates, relevantly, $\tau_{\mathrm{m}}=0.071 \theta^{2}$ $-3.644 \theta+97.204$; the angle made the mixing time reach a minimal value was $\theta=25.662^{\circ}$. For the combined blowing process with a gas top blowing rate of $65.35 \mathrm{Nm}^{3} / \mathrm{h}$, the mixing time also shortened monotonously with raising of the angle between each tuyere, but the reduced amplitudes were still smaller, about $(6-10) \mathrm{s}$. These situations are not entirely similar to the results given in the preliminary investigation, ${ }^{2,3)}$ according to which, using 5 tuyeres with an angular separation of $22.5^{\circ}$ or $27^{\circ}$ can all provide a better mixing effectiveness for the combined blowing.

The results obtained showed that, generally, for simple side blowing process, increasing the angular separation between each tuyere in a permissible and possible range (dependent on the tuyere number utilized) would be beneficial to the mixing in the bath. For combined blowing process, the influence of the angle between each tuyere on the mixing in the bath would also relate to the tuyere number and gas top blowing rate employed. As far as the mixing in the bath is concerned, for the $120 \mathrm{t}$ combined blowing AOD converter equipped with 7 tuyeres, an angle of $18^{\circ}$ between each tuyere in existing use would be an unsuitable tuyere arrangement, and the mixing effectiveness at an angular separation of $22.5^{\circ}$ between each tuyere would be better.

This kind of the influence of the angular separation between each tuyere on the mixing in the bath is corresponding to its effect on the gas stirring and liquid flow in the bath during the blowing process. Qualitatively, at a given gas side blowing rate, an excessively large or small angle between each tuyere will intensify the interactions among the gas streams, and increase the stirring power consumption and lower the gas agitation efficiency. ${ }^{1,7)}$ With a given tuyere number and gas blowing rate, the larger the angular separation between each tuyere, the weaker the interaction among the gas streams, the lower the stirring power consumption, thus the higher the agitation efficiency becomes. Relatively, a decrease in the angle between each tuyere makes the area of the sector zone included by the side tuyeres and the corresponding area occupied by the gas-liquid two-phase zone at the bath surface reduce, thus lowering the efficiency and homogeneity of the gas stream stirring to the bath.

\subsection{Effect of Side Tuyere Number on Mixing Charac- teristics}

With regard to the effect of the side tuyere number on the mixing time in the bath, the situation is not so simple. Similar to that for the gas stirring and liquid flow, the number, as another key factor, is also not an independent variable for the mixing in the bath. At a given gas side blowing rate and tuyere position, the relevant areas of the sector zones included by the tuyeres (the direct agitation zones) to different tuyere numbers are different from each. Additionally, the gas blowing rates for single tuyere, the outlet parameters of gas stream, the horizontal penetrations, and the interactions among the gas streams and others are different from each other. Correspondingly, the gas stirring actions and liquid flow patterns in the bath as well as the mixing results are also different from each other. Figures 9 to 11 and the concerned experimental data demonstrated that if only taking the mixing in the bath into account, for the simple side blowing at an angle of $18^{\circ}$ between each tuyere, using 5 or 6 tuyeres was just slightly better than using 7 tuyeres. Nevertheless, the appropriate mixing efficiencies were all not so high. With an angular separation of $22.5^{\circ}$ between each tuyere, using 7 tuyeres would be still better. When the angle between each tuyere was $27^{\circ}$, it would be more suitable to use 6 tuyeres (in the case, it is impossible to take 7 tuyeres), the mixing effectiveness attained was roughly equivalent to that of using 5 tuyeres with an angular separation of $31.5^{\circ}$ (Fig. 7). Accordingly, for the simple side blowing process, 7 tuyeres with $22.5^{\circ}, 6$ tuyeres with $27^{\circ}, 5$ tuyeres with $31.5^{\circ}$, and 4 tuyeres with $45^{\circ}$ would all be a proper and advisable plan for the tuyere equipment and arrangement, and 7, 6 and 5 tuyeres with an included angle of $18^{\circ}$ would be improperly taken. For the combined blowing with a gas top blowing rate of $79.87 \mathrm{Nm}^{3} / \mathrm{h}$, when using an angular separation of $18^{\circ}$ or $22.5^{\circ}$ between each tuyere, the mixing efficiency in the bath with 5 tuyeres was relatively better, and it was still better at 5 tuyeres with an angle of $22.5^{\circ}$. When taking an angle of $27^{\circ}, 6$ tuyeres would be the best advisable scheme; and 5 tuyeres with $31.5^{\circ}$ would not be suitably utilized because of a worst mixing effectiveness. Under the conditions of the combined blowing with a gas top blowing rate of $72.61 \mathrm{Nm}^{3} / \mathrm{h}$, an approximately equivalent and good mixing efficiency could all be achieved by using 7 or 6 tuyeres with $22.5^{\circ}, 6$ tuyeres with $27^{\circ}, 5$ tuyeres with $31.5^{\circ}$, and 4 tuyeres with $45^{\circ}$. When the gas top blowing rate being smaller $\left(65.35 \mathrm{Nm}^{3} / \mathrm{h}\right), 7$ tuyeres with $22.5^{\circ}, 6$ tuyeres with $27^{\circ}$, as well as 5 tuyeres with $31.5^{\circ}$ and 4 tuyeres with $45^{\circ}$ would all be a suitable and advisable scheme of the tuyere equipment and arrangement.

At a given angle between each tuyere and gas side blow- 
ing rate, on the whole, increasing the tuyere number will be of a certain benefit to the mixing in the bath. However, it can decrease the gas flow rate for single tuyere, thus making the horizontal penetrations of side gas streams shorten and the high temperature (reaction) zone moving towards, even close to the sidewall around the tuyere outlets, leading to lowering the refractory lining life. Compositely taking account of the situations for the simple side and combined blowing with different gas blowing rates, it had better using 6 tuyeres when taking an angle of $27^{\circ}$ between each tuyere. Appropriately, a considerably high mixing efficiency would be able to be reached at all the operating modes in the present work.

\subsection{Influence of Gas Blowing Rate on Mixing Charac- teristics}

Figures 12-14 clearly indicated that the gas flow rate had a very strong effect on the mixing in an AOD converter bath; particularly, the gas blowing rate from the main tuyeres had a determinant role. Furthermore, at a given tuyere number and angular separation between each tuyere, corresponding to the operating modes in this work, the mixing times all presented non-linear relations with the total gas blowing rate for both simple side and combined blowing.

For the situation at a given gas top blowing rate of $79.87 \mathrm{Nm}^{3} / \mathrm{h}$ and a given tuyere number of 7 with an angle of $18^{\circ}$ between each tuyere, curve fittings of the experimental data regarding the mixing time in the bath at different gas blowing rates were conducted in terms of linear, quadratic and cubic polynomial, respectively. The fitting result according to cubic polynomial is best, being able to reflect fully the influencing pattern of the gas blowing rate on the mixing time. The curves given in Figs. 12-14 were all resulted from fitting of the experimental data at the appropriate operating modes in terms of cubic polynomial. It can be seen that at the given tuyere numbers and angles between each tuyere, the mixing times in the bath all possessed a changing tendency to gradually reduce first and then raise with increasing in the total gas blowing rate for both simple side and combined blowing under the conditions of the present work. When rise in the total gas side blowing rate to a certain value, the prolongation of the mixing time was gradually slowing down with the rate further increasing; and in a certain total gas flow rate range, for example, at $(61.74-82.67) \mathrm{Nm}^{3} / \mathrm{h}$, there all were a region with the shortest mixing time.

It is worthwhile to be mentioned that the experimental results obtained by using 4 tuyeres with an angle of $45^{\circ}$. This equipment and arrangement of tuyeres could also offer a better mixing effectiveness for both the simple side blowing and the combined blowing with different total gas flow rates.

The changing pattern of the mixing time in the bath at a given tuyere equipment and arrangement (the tuyere number and position) with the gas side blowing rate also corresponds entirely to the gas stirring and fluid flow condition in the bath. At a given angular separation between each tuyere, the agitation work imported into the bath from a gas stream with a low flow rate would be lower. It would be difficult to offer excellent stirring. With an excessively large gas side blowing rate, the effective gas stirring work would instead reduce, like that in the case with an excessively small or large angle between each tuyere. In a sense, a reasonable and suitable blowing technology should be able both to provide a high mixing efficiency and to ensure the bath to be dynamic and stable. However, for a practical process, the determination of the specific gas flow rates of the side and top blowing is not according to the mixing time but based on the real requirement of the refining reactions. Relatively, the influence of the tuyere equipment and arrangement on the mixing in the bath would be more significant and more worth to be noticed, and have a more practical meaning for selecting and optimizing the tuyere number and position.

The related results also clearly showed that at the given tuyere equipments and arrangements as well as gas side blowing rates, the existence and action of a gas jet from the top lance could all prolong obviously the mixing time in the bath. This again confirmed that the conclusion with a minor effect of the gas top blowing jet on the fluid flow and mixing in the bath ${ }^{4,6)}$ is not true. As mentioned before, ${ }^{1-3)}$ under the impact of the gas blowing jet from the top lance, the interaction of the liquid motion generated by the gas top blowing jet with the liquid motion caused by the gas side blowing streams can change the liquid flow pattern in the bath. Moreover, it can increase the liquid turbulence and the total stirring power consumption, thus resulting in a decrease in mixing efficiency. The larger the gas top blowing rate, the larger the appropriate impinging force exerted on the bath liquid surface, the stronger the interaction between the gas top blowing jet and the gas side blowing streams, and the more remarkable the decrease in the mixing efficiency becomes. For different tuyere numbers and positions, the effects of the gas top blowing jet with a given flow rate upon the fluid flow and mixing in the bath would be different from each other. Relative to the case of using 7 tuyeres, the influence of the gas top blowing rate on the mixing in the bath with 6 tuyeres would be weaker, and still smaller when using 5 tuyeres. These are also relevant to different gas agitations and liquid flow patterns in the bath at the given various operating modes.

Considering the influences of the factors, the following relationships were obtained from the experimental data,

for simple side blowing:

$$
\tau_{\mathrm{m}}=\left\{\begin{array}{r}
13.95\left(Q_{\mathrm{m}}\right)^{0.1359}\left(Q_{\mathrm{s}}\right)^{-0.1155}\left(S / S_{0}\right)^{-0.4448}\left(N / N_{0}\right)^{-0.4483} \\
\left(18^{\circ}-27^{\circ}\right) \\
11.54\left(Q_{\mathrm{m}}\right)^{0.1554}\left(Q_{\mathrm{s}}\right)^{-0.1229}\left(S / S_{0}\right)^{-0.7958}\left(N / N_{0}\right)^{-1.2021} \\
\left(27^{\circ}-45^{\circ}\right)
\end{array}\right.
$$

for combined side and top blowing:

$$
\tau_{\mathrm{m}}=\left\{\begin{array}{r}
1.102\left(Q_{\mathrm{m}}\right)^{0.1105}\left(Q_{\mathrm{s}}\right)^{-0.1043}\left(Q_{\mathrm{t}}\right)^{0.6653}\left(S / S_{0}\right)^{-0.2954}\left(N / N_{0}\right)^{-0.1175} \\
\left(18^{\circ}-27^{\circ}\right) \\
0.697\left(Q_{\mathrm{m}}\right)^{0.1270}\left(Q_{\mathrm{s}}\right)^{-0.0940}\left(Q_{\mathrm{t}}\right)^{0.8336}\left(S / S_{0}\right)^{-0.3268}\left(N / N_{0}\right)^{-0.5283} \\
\left(27^{\circ}-45^{\circ}\right)
\end{array}\right.
$$

where $S$ and $S_{0}$ are, respectively, the area of the sector section included between the axes of the two adjacent side tuyeres and the cross-sectional area of the bath in $\mathrm{m}^{2} . N$ and $N_{0}$ 
are, respectively, the tuyere number used and the standard tuyere number, and $N_{0}$ was taken to be 2 and $N$ to be 4-7 in this work. Subscripts $\mathrm{m}, \mathrm{s}$ and $\mathrm{t}$ denote the main tuyere, the subtuyere and the top lance, respectively. Obviously, in both the simple side blowing and the combined blowing, the gas blowing rate of the main tuyeres has a strong influence on the liquid mixing in the bath; and the gas streams from the subtuyeres have a physical shielding effect on the main tuyere streams. A proper increase in the gas blowing rate of the subtuyeres would enhance the mixing efficiency in the bath. These are similar to those obtained for the refining process in an $18 \mathrm{t}$ AOD vessel with two tuyeres. ${ }^{7)}$ Moreover, the gas top blowing jet could make the mixing time in the bath prolong. It is necessary to point out that $S$ in Eqs. (1) and (2) varies with the change in $N$. Furthermore, the two equations are somewhat different from those given in the preliminary investigation. ${ }^{2,3)}$

From the results gained in the present work and noticing the change in the gas blowing rate during the whole actual refining, a desirable mixing efficiency in the bath at the blowing periods would be able to be achieved by using 6 tuyeres with $27^{\circ}$, for the $120 \mathrm{t}$ combined side and top blowing AOD converter.

\subsection{Relationship of Gas Agitation Work with Mixing Time}

From the calculated results of the gas agitation power densities $^{1)}$ and the experimental data, the relationships of the mixing time in the bath with the densities were gotten as follows,

under the conditions of simple side blowing,

$$
\tau_{\mathrm{m}}=\left\{\begin{array}{r}
14.78\left(\varepsilon_{\mathrm{mm}}\right)^{0.1115}\left(\varepsilon_{\mathrm{ms}}\right)^{-0.1109}\left(S / S_{0}\right)^{-0.4446}\left(N / N_{0}\right)^{-0.4297} \\
\left(18^{\circ}-27^{\circ}\right) \\
12.38\left(\varepsilon_{\mathrm{mm}}\right)^{0.1241}\left(\varepsilon_{\mathrm{ms}}\right)^{-0.1165}\left(S / S_{0}\right)^{-0.7944}\left(N / N_{0}\right)^{-1.1807} \\
\left(27^{\circ}-45^{\circ}\right)
\end{array}\right.
$$

under the conditions of combined side and top blowing,

$$
\tau_{\mathrm{m}}=\left\{\begin{array}{r}
9.75\left(\varepsilon_{\mathrm{mm}}\right)^{0.0911}\left(\varepsilon_{\mathrm{ms}}\right)^{-0.1005}\left(\varepsilon_{\mathrm{mt}}\right)^{0.1865}\left(S / S_{0}\right)^{-0.2955}\left(N / N_{0}\right)^{-0.1032} \\
\left(18^{\circ}-27^{\circ}\right) \\
10.5\left(\varepsilon_{\mathrm{mm}}\right)^{0.1014}\left(\varepsilon_{\mathrm{ms}}\right)^{-0.0892}\left(\varepsilon_{\mathrm{mt}}\right)^{0.2320}\left(S / S_{0}\right)^{-0.3261}\left(N / N_{0}\right)^{-0.5106} \\
\left(27^{\circ}-45^{\circ}\right)
\end{array}\right.
$$

Despite the fact that $\varepsilon_{\mathrm{m}}$ has a bearing on $T_{\mathrm{g}}$ and $Q$ (when discharging at subsonic velocity, $T_{\mathrm{g}}$ would decrease with an increase in $Q$ ), these two equations are in a form completely similar to Eqs. (1) and (2). As mentioned before, ${ }^{1)}$ at a given total gas side blowing rate, the agitation power density of side blowing gas changes with the variation of the side tuyere number used. In the combined blowing process, the contribution of the gas top blowing jet to the total agitation power density would also alter with the changes in the side tuyere number and gas side blowing rate employed. Here, the interactions between the gas top blowing jet and the gas side blowing streams as well as among the gas side blowing streams were all ignored.

\subsection{Dimensionless Correlation of Mixing Time}

The dimensional analysis showed that for mixing in the bath during the combined side and top blowing, the following equations are held,

for simple side blowing:

$$
\begin{aligned}
f\left(\frac{u_{\mathrm{gm}} \tau_{\mathrm{m}}}{d_{\mathrm{m}}}, \frac{u_{\mathrm{gs}} \tau_{\mathrm{m}}}{d_{\mathrm{s}}}, \frac{\rho_{\mathrm{gm}} u_{\mathrm{gm}}^{2}}{\rho_{1} g d_{\mathrm{m}}}, \frac{\rho_{\mathrm{gs}} u_{\mathrm{gs}}^{2}}{\rho_{1} g d_{\mathrm{s}}},\right. \\
\left.\frac{H_{1}}{D_{\mathrm{e}}}, \frac{D_{\mathrm{e}}}{d_{\mathrm{m}}}, \frac{D_{\mathrm{e}}}{d_{\mathrm{s}}}, \frac{\rho_{\mathrm{gm}}}{\rho_{1}}, \frac{\rho_{\mathrm{gs}}}{\rho_{1}}, \frac{S}{S_{0}}, \frac{N}{N_{0}}\right)=0
\end{aligned}
$$

for combined side and top blowing:

$$
\begin{aligned}
& f\left(\frac{u_{\mathrm{gm}} \tau_{\mathrm{m}}}{d_{\mathrm{m}}}, \frac{u_{\mathrm{gs}} \tau_{\mathrm{m}}}{d_{\mathrm{s}}}, \frac{u_{\mathrm{gt}} \tau_{\mathrm{m}}}{d_{\mathrm{t}}}, \frac{\rho_{\mathrm{gm}} u_{\mathrm{gm}}^{2}}{\rho_{1} g d_{\mathrm{m}}}, \frac{\rho_{\mathrm{gs}} u_{\mathrm{gs}}^{2}}{\rho_{1} g d_{\mathrm{s}}}, \frac{\rho_{\mathrm{gt}} u_{\mathrm{gt}}^{2}}{\rho_{1} g d_{\mathrm{t}}},\right. \\
& \left.\frac{H_{1}}{D_{\mathrm{e}}}, \frac{D_{\mathrm{e}}}{d_{\mathrm{m}}}, \frac{D_{\mathrm{e}}}{d_{\mathrm{s}}}, \frac{D_{\mathrm{e}}}{d_{\mathrm{t}}}, \frac{\rho_{\mathrm{gm}}}{\rho_{1}}, \frac{\rho_{\mathrm{gs}}}{\rho_{1}}, \frac{\rho_{\mathrm{gt}}}{\rho_{1}}, \frac{S}{S_{0}}, \frac{N}{N_{0}}\right)=0
\end{aligned}
$$

where $D_{\mathrm{e}}$ is the equivalent diameter of the bath. For simple side blowing, taking $\bar{u}=\left[u_{\mathrm{gm}} Q_{\mathrm{m}}+u_{\mathrm{gs}} Q_{\mathrm{s}}\right] /\left[Q_{\mathrm{m}}+Q_{\mathrm{s}}\right]$ and $\overline{d_{1}}$, $\overline{d_{2}}$, and $\bar{d}$ to be, respectively, the equivalent diameters of the main tuyeres and subtuyeres and the total of the multiple tuyeres combined into one (the effective cross-sectional areas are relevantly equal), the results achieved from the experimental data are presented in Fig. 15. The straight lines in this figure are obtained from the following equation,

$$
\frac{\bar{u} \tau_{\mathrm{m}}}{\bar{d}}=\left\{\begin{array}{r}
17878\left(F r_{\mathrm{m}}^{\prime}\right)^{0.5418}\left(F r_{\mathrm{s}}^{\prime}\right)^{-0.0686}\left(S / S_{0}\right)^{-0.4431}\left(N / N_{0}\right)^{-0.6867} \\
\left(18^{\circ}-27^{\circ}\right) \\
15556\left(F r_{\mathrm{m}}^{\prime}\right)^{0.5342}\left(F r_{\mathrm{s}}^{\prime}\right)^{-0.0724}\left(S / S_{0}\right)^{-0.8329}\left(N / N_{0}\right)^{-0.4543} \\
\left(27^{\circ}-45^{\circ}\right)
\end{array}\right.
$$
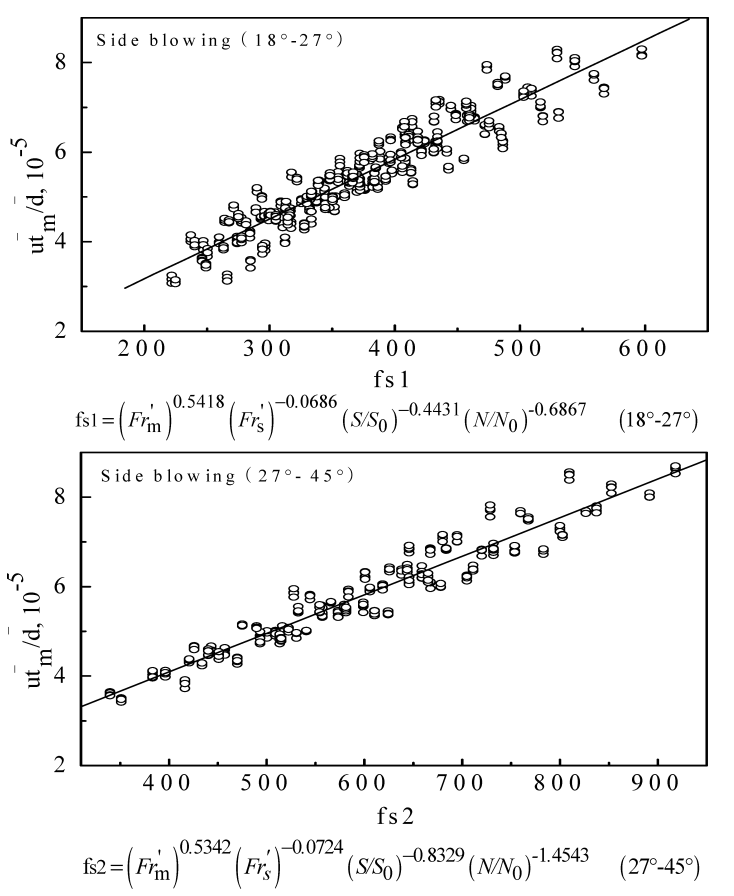

Fig. 15. Dimensionless correction of mixing time in the $120 \mathrm{t}$ AOD model bath under the conditions of simple side blowing. 

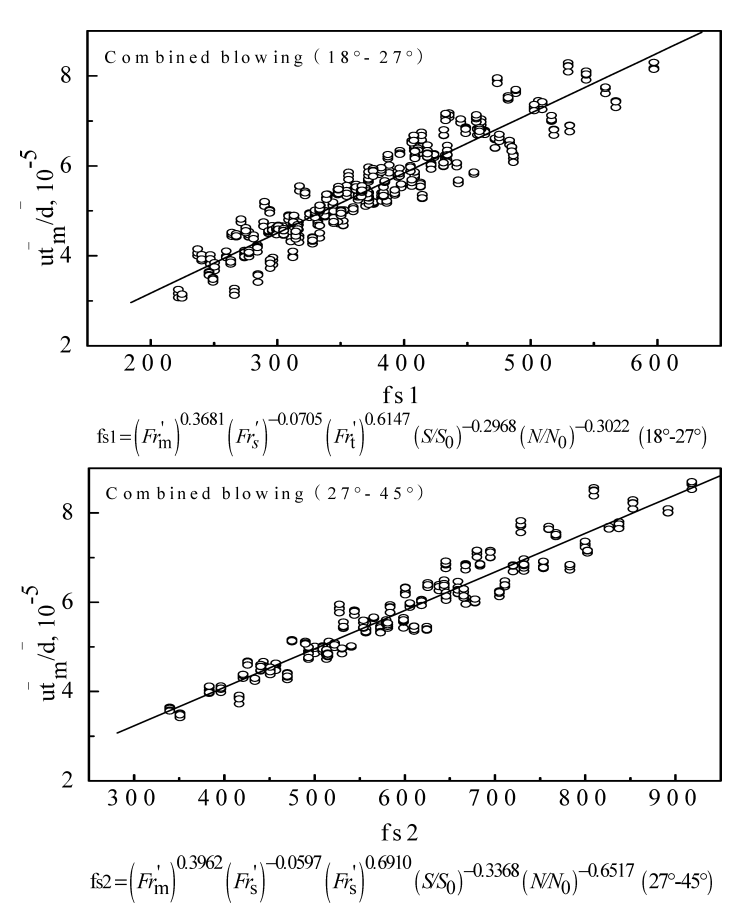

Fig. 16. Dimensionless relationship of mixing time in the $120 \mathrm{t}$ AOD model bath under the conditions of combined side and top blowing.

For combined side and top blowing, taking $u=$ $\left[u_{\mathrm{gm}} Q_{\mathrm{m}}+u_{\mathrm{gs}} Q_{\mathrm{s}}+u_{\mathrm{gt}} Q_{\mathrm{t}}\right] /\left[Q_{\mathrm{m}}+Q_{\mathrm{s}}+Q_{\mathrm{t}}\right]$ and the same $\overline{d_{1}}, \overline{d_{2}}$, and $\bar{d}$, the corresponding results obtained from the experimental data are illustrated in Fig. 16. The straight lines in this figure are given from Eq. (8),

$$
\frac{\bar{u} \tau_{\mathrm{m}}}{\bar{d}}=\left\{\begin{array}{r}
1163\left(F r_{\mathrm{m}}^{\prime}\right)^{0.3681}\left(F r_{\mathrm{s}}^{\prime}\right)^{-0.0705}\left(F r_{\mathrm{t}}^{\prime}\right)^{-0.6147}\left(S / S_{0}\right)^{-0.2968}\left(N / N_{0}\right)^{-0.3022} \\
\left(18^{\circ}-27^{\circ}\right) \\
768.9\left(F r_{\mathrm{m}}^{\prime}\right)^{0.3962}\left(F r_{\mathrm{s}}^{\prime}\right)^{-0.0597}\left(F r_{\mathrm{t}}^{\prime}\right)^{-0.6910}\left(S / S_{0}\right)^{-0.3368}\left(N / N_{0}\right)^{-0.6517} \\
\left(27^{\circ}-45^{\circ}\right)
\end{array}\right.
$$

Figures 15 and 16 with Eqs. (7) and (8) also indicate clearly that in both simple side and combined blowing, the gas blowing rate of the main tuyeres has a key role on the liquid mixing in the bath. Increasing suitably the gas flow rate of the subtuyere can improve the mixing efficiency, and the gas top blowing jet prolongs the mixing time. In view of the high kinematic similarity of the model to its prototype maintained under the conditions of the present work, the results attained would be able to reflect more fully and more authentically the mixing characteristics of the fluids in the prototype bath than those given in the preliminary investigation. ${ }^{2,3)}$ This has been verified in practice during the manufacturing of stainless steel in the $120 \mathrm{t}$ AOD converter. Only using a more suitable angular separation between each tuyere has made the life of the refractory lining of the converter raise by a factor of about 1.3 , and made the technical and economic indications of the refining process improve remarkably. The details will be described in Part IV of the present work. ${ }^{8,9)}$

\section{Conclusions}

Based on water modeling of the gas stirring and fluid flow in the bath, the fluid mixing characteristics in the bath during the combined side and top blowing AOD refining process of stainless steel were investigated on a water model unit of a $120 \mathrm{t}$ AOD converter. The results indicated that,

(1) The combined side and top blowing AOD refining process has indeed a good mixing effectiveness.

(2) The gas side blowing rate of the main tuyeres has a key role on the liquid mixing in the bath; with an obvious physical shielding effect of the gas streams from the side subtuyeres on the gas streams of the main tuyeres, increasing suitably the gas blowing rate of the subtuyeres can raise the mixing efficiency in the bath.

(3) The gas top blowing jet can make the mixing efficiency decrease and the mixing time prolong evidently.

(4) For a simple side blowing, at a given tuyere number and gas side blowing rate, increasing the angular separation between each tuyere is beneficial to shortening the mixing time. With a given angle between each tuyere and gas side blowing rate, increasing the tuyere number can not necessarily gain definitely a similar result. In addition, it can make the high temperature zone move towards the sidewall around the tuyere outlets and lower the life of the refractory lining due to reducing the gas flow rate of single tuyere and the horizontal penetration.

(5) Relevant to the oxygen top bowing rate of $6600 \mathrm{Nm}^{3} / \mathrm{h}$ used in the practice, the tuyere equipments and arrangements of 5 tuyeres with $22.5^{\circ}$ and 6 tuyeres with $27^{\circ}$ can all provide a roughly equivalent and good mixing effectiveness.

(6) With respect to the mixing in the bath only, for the $120 \mathrm{t}$ AOD converter, the existing equipment and arrangement of 7 tuyeres with $18^{\circ}$ will not be advisable under the blowing operations utilized in the real process; using 6 tuyeres with $27^{\circ}$ can offer a perfect mixing in all the various refining periods.

(7) The relationships between mixing time and related parameters are presented by Eqs. (1), (2), (3), (4), (7) and (8), respectively.

\section{Acknowledgement}

The authors gratefully acknowledge the combined support of The National Natural Science Foundation of China and Shanghai Bao Steel (Group) Corporation (Grant No. 50374047).

\section{REFERENCES}

1) J.-H. Wei, H.-L. Zhu, H.-J. Wang and H.-B. Chi: ISIJ Int., 50 (2010), No. 1,17 .

2) J.-H. Wei, H.-L. Zhu, S.-L. Yang, J.-C. Ma, G.-M. Shi, Q.-Y. Jiang, H.-B. Chi, L.-B. Che and K. Zhang: Steel Res. Int., 76 (2005), No. 5, 362.

3) X.-C. Wang: M. D. Thesis, Shanghai University, (2004).

4) T. Fabritius, P. Kupari and J. Harkki: Scand. J. Metall., 30 (2001), No. $1,57$.

5) T. M. J. Fabritius, P. T. Mure, P. A. Kupari, V. Juntunen and J. J. Härkki: Steel Res., 72 (2001), No. 7, 237.

6) T. M. Fabritius, P. T. Mure and J. J. Harkki: ISIJ Int., 43 (2003), No. $8,1177$.

7) J.-H. Wei, J.-C. Ma, Y.-Y. Fan, N.-W. Yu, S.-L. Yang, S.-H. Xiang and D.-P. Zhu: Ironmaking Steelmaking, 26 (1999), No. 5, 363.

8) J.-H. Wei, H.-L. Zhu, H.-B. Chi and H.-J. Wang: Proc. 13th National Metallurgical Reaction Engineering, CMS, Beijing, China, (2009), 637.

9) Q.-Y. Jiang, J.-H. Wei, G.-M. Shi, H.-L. Zhu, H.-B. Chi and H.-J. Wang: Proc. 13th National Metallurgical Reaction Engineering, CMS, Beijing, China, (2009), 633. 